\title{
lconografía santiaguista y espiritualidad franciscana en la nueva España (siglo XVI)
}

\author{
JoAQUIN MONTES BARDO
}

\section{LA PROVINCIA FRANCISCANA DEL SANTO EVANGELIO}

Conquistado Tenochtitlán, en la primavera de 1524 llega la primera expedición eclesiástica con letras apostólicas a la Nueva España: la constituian doce franciscanos que pasarán a la Historia como Los Doce Apóstoles de México. Procedian de la Custodia de San Gabriel de Extremadura, cuatro años antes elevada a provincia al desgajarse de Santiago de Galicia por más perfección, en la consideración de sus cronistas '. El propio Hernán Cortés saldrá a recibirlos, escenificando un encuentro con todo el simbolismo de la cultura humanista de la época ${ }^{2}$. Se establecen en lo que será el espacio más cristianizado del Virreinato y donde la cultura española enraíza decididamente: es decir, tienen su asiento en el riñón y en lo mejor y más poblado de las Indias, que es la tierra o comarca del Arzobispado de México y' el obispado de Tlaxcala ${ }^{3}$. Este altiplano de México es el escenario fundamental de la conquista cortesiana y corazón de las altas cultura del Anáhuac. De acuerdo con ello, su iconografía se desplegará sobre las ruinas de los viejos centros ceremoniales aztecas, resultando de esto modo más convincente para los nuevos neófitos que todos los tratados apologéticos de sus misioneros.

$Y$ coincidiendo con el erasmismo en su necesidad de interiorizar la religión, desarrollarán una misionología tendente a establecer una nueva

\footnotetext{
Jeronimo de Mendieta. Relación de la Descripción de la Provincia del Santo Evangelio que es en Las Indias Occidentales que llaman ia Nueva España. Pág. 53. México, 1975.

Jeronimo de mendieta. Historia Eciesiástica Indiana. Vol. 2. Lib. 3. Cap. 12. Pág. 53. México, 1945.

JoAquin Garcia lCazbalceta. Codice tranciscano. Relación del Santo Evangelio de 1569. Pág. 3,4. México, 1889-1892.
} 
cristiandad a imagen de la apostólica. De aquí que la primera iconografía que divulguen, después de la cristífera y mariana, sea la apostólica de forma que, casi en cada provincia donde hay monasterio hay advocación de los doce apóstoles ${ }^{4}$. De éstos, Pedro y Pablo, con Santiago, alcanzan el mayor desarrollo iconográfico.

\section{FRANCISCANISMO SANTIAGUISTA}

Historia y leyenda han hecho de Santiago el Mayor un símbolo de la nación española. La trayectoria de su iconografia manifiesta las vicisitudes que, a través de los siglos, van configurando una visión peculiar de su figura. El patrono de España navegará hacia la América española, en una aventura superior a la propia tradición que lo hace arribar, después de muerto, al Finis Terrae europeo.

En Santiago de la Nueva España confluyen: la figura del Apóstol de Cristo; la expresión española de su fe religiosa; la condición franciscana y santiaguista de sus promotores; y el substrato azteca donde se asienta, una sociedad teocrática y militarista. El resultado será un Santiago, iconográficamente no diverso, pero substancialmente diferente en su iconología.

El franciscanismo español se gestó junto a la tumba del Apóstol, en el antiguo Campo de la Estrella, al que peregrina San Francisco: Ambos nos engendraron en Jesucristo, uno y otro nos hicieron profesar el evangelio ${ }^{5}$, expresará el cronista santiaguista que ilustra su obra con un grabado ejemplificador en el que aparece San Francisco plantando el árbol de su orden óptimo de frutos; Santiago que lo riega y Dios Padre presidiendo la escena; un texto parafrasea el pensamiento paulino de I Co 3,6: ego plantavi (San Francisco), ego regavi (Santiago), ego incrementum dedit (Dios Padre). La propagación de la fe cristiana en la Nueva España es consustancial a esta iconografía. La propia liturgia católica le aplica en su festividad el Salmo 18: In omnem terram exivit sonus eorum et in fines orbis terrae verba eorum ${ }^{\circ}$.

San Francisco peregrina Compostela en los comienzo de la fundación de su orden, cuando los frailes eran pocos y aun no tenian conventos, le

\footnotetext{
- Toribio Motolinia. Historia de los indios de la Nueva España. Trat. 1. Cap. 3. Pag. 22. México, 1979. Jacobo de CASTRo. Árbol cronológico de la Santa Provincia de Santiago. Lib. I. Cap. 2. Madrid, 1976.

" Missale Romano Seraphicum. Jacobus Apost. Offertorium. Mechliniae, MCMxxIV.
} 
acompaña su discípulo Bernardo de Quintaval y, estando de noche en oración en la iglesia del Santo Apóstol, reveló Dios a San Francisco que tenia que fundar muchos conventos en el mundo... por esta revelación comenzó San Francisco a fundar conventos en aquellas tierras?

San Francisco, desde el monte Pedroso vecino del Nerio o de Finis Terrae $^{8}$, como otro apóstol, transmitirá el evangelio en una segunda cristianización que renovará también la espiritualidad franciscana. Con el descubrimiento de América, los hijos que mejor continúan su espíritu prolongarán el limite de lo desconocido, desde California a la tierra de Fuego. Serán Los Doce, profesos en la Provincia de Santiago, quienes hagan realidad histórica la visión del Seráfico Padre, cabe el sepulcro del Apóstol.

El viaje de San Francisco a España, albergando el secreto deseo de alcanzar el martirio entre musulmanes, hace que el franciscanismo español nazca con vocación misionera. Esta dimensión será vivida por Los Doce en su propósito de vuelta a las fuentes originales de su espiritualidad, provocando así un auténtico renacimiento religioso en América.

El primer fruto del deseo de martirio en San Francisco llega con los Protomártires de Marruecos: ut, sicut ipse Franciscus Orientis, ita hi Occidentis populos fidei veritate imbuere, el Christi lucrifacerent ${ }^{9}$. El martirio se consumó en 1220 y sus restos, rescatados por Don Pedro de Portugal, estimularán a profesar en la misma orden al canónigo regular que será más tarde San Antonio de Padua, o de Lisboa, martyrii cupiditate incensus. Los Doce de México, por su formación santiaguista, hicieron de este episodio la base de su misionología. Lo demuestra el reiterado intento de su prelado Fray Martín de Valencia persiguiendo pasar a África; de Fray Luis de Fuensalida, segundo custodio del Santo Evangelio, a quien se lo impide San Pedro de Alcántara; de Fray Antonio Ortiz, provincial de San Gabriel e íritimo de Fray Martín, que lo realiza ${ }^{10}$.

Desde los comienzos, el Norte de África estará en el horizonte misionero de los franciscanos españoles, reiterando en su subconsciente colectivo el proyecto secular de la Reconquista cristiana; la posibilidad de instaurar su forma de vida en un mundo nuevo; el escape a las tensiones en la interpretación de su espiritualidad y el cumplimiento del fervor misionero de San Francisco. En la antesala de América, Cisneros, con sus campañas de

Florecillas de San Francisco. Primera parte. Cap. 3. Pág. 88. Madrid, 1975. Jacobo de Castro. Árbol Cronológico. Cap. 1. Pág. 18.

Jeronimo de Mendieta. Historia Eclesiástica Indiana. Lib. 5. Cap. 4. Pág. 21. Jeronimo de Mendieta. Historia Eclesiástica Indiana. Lib. 5. Cap. 4. Pag. 21. 
África, pretende el aniquilamiento del Islam, la reconstrucción de la cristiandad de los primeros siglos y la reconquista de Jerusalén".

No es forzado establecer unas vidas paralelas entre el mínimo y dulce Francisco de Asís y Santiago Matamoros. La ascética cristiana es, por definición, combate, y, aún la existencia humana: militia est vita hominis super terram. (Jb. 7. 1). Es San Pablo quien expresa mejor el concepto cuando estimula a Timoteo: Soporta las fatigas conmigo, como un buen soldado de Cristo Jesús (2. Tm. 2. 3).

Los primeros hagiógrafos de San Francisco le aplican los títulos de la gloria militar: Caballero del Crucificado, Gonfaloniero de Cristo, Condestable del Ejército Santo. Con mentalidad de cruzado emprende su peregrinación a Tierra Santa, resultando de la misma la Custodia franciscana de los Santos Lugares. Antes de su conversión había soñado con la gloria de las armas ${ }^{12}$, que abandonará por la conquista espiritual: se despoja del cinto en el que pendía la espada y en su lugar se ciñe una cuerda áspera y nudosa ${ }^{13}$. Sus Tres Ordenes las concibe como la triple milicia de los escogidos.

El franciscanismo español acuñará una interpretación menos lírica y más épica, en consonancia con su vivencia secular de hombres de frontera. La "conquista espiritual» la desplegarán en América; cuando convidaba a ello el mesianismo de la época, desde la ideología visionaria de Colón: Jerusalén y el monte Sión ha de ser edificado por mano de cristiano; quién ha de ser, Dios por boca del profeta en el Salmo 14 lo dice. El abad Joaquín dijo que éste habría de salir de España ${ }^{17}$.

\section{EL CABALLERO DE LA CRUZ BERMEJA}

Esta historia de cristianismo militante esculpe la figura de Santiago Matamoros: Los moros invocan a Mahoma y los cristianos a Santiago, canta el juglar del Cid, quien entra en batalla en nombre del Creador $y$ del apóstol Santiago ${ }^{15}$. Religiosidad medieval, guerrera y agraria, que implantarán los españoles en América ${ }^{16}$. Que, como antes, les harán arrostrar las dificultades para valer y poder más según el mundo y hacerse rico,

Marcel Bataillon. Erasmo y España. Cap. 1. Pág. 52. Madrid, 1983.

Tomas de Celano. Vida Primera de San Francisco. Cap. 2. No 5. Pág. 256. Madrid, 1975.

San Buenaventura. Leyenda Mayor. Cap. 3. N 1. Pág. 477. Madrid, 1975.

Cristobal Colón. Diario. Cuarto Viaje. Pág. 221. Madrid, 1985.

Anónimo. Cantar del Cid. Canto Primero. v. 731 y Canto Segundo. v. 1690. Madrid, 1976.

16. Claudo Sanchez Albornoz. La Edad media española y la empresa americana. Cap. 7. Pág. 53. Madrid, 1983. 
cuando vino a esta tierra ${ }^{17}$. Santiago Matamoros respondía a las urgencias de triunfo terreno y consecución del más allá, que

\author{
los buenos religiosos \\ gánanlo con oraciones \\ e con lloros; \\ los caballeros famosos \\ con trabajos e aflicciones \\ entre moros ${ }^{18}$.
}

Esta concepción de la sociedad se prolongó en la conquista de la Nueva España: mientras el conquistador luchaba, los franciscanos no estaban descuidados de ayudar a la fe y a los que por ella peleaban, con oraciones y plegarias '19. Actitud extraída de la Biblia: durante la batalla entre los israelitas y los amalecitas, mientras Moisés tenía alzadas las manos, prevalecia Israel; pero cuando las bajaba, prevalecía Amalec. (Ex.17.11). La vivencia castellana fronteriza, enlaza con un franciscanismo que se orienta a una vida más alta, entrevista en su horizonte espiritual.

Santiago se enmarca en una sociedad que participa de la exaltación bíblica del pastor, frente al labrador, en un paralelismo singular: el pueblo de Israel marchó hacia la conquista de la Tierra Prometida; Castilla a recuperar su solar enajenado, al menos eso creían ellos, por los moros; los dos pueblos frente al enemigo de su fe; los dos poseedores de una religiosidad militante. Sin ello, no se entiende el comportamiento de soldados y mendicantes en la Nueva España cuya empresa, como la cruzada peninsular es, a la vez, botín, válvula migratoria y exaltación fiducial. Sus componentes religiosos, militares y nobiliarios, elevarán a categoria de símbolo, la clásica estampa del Apóstol, Cruzado y Caballero.

En el primer tercio del siglo apunta un criticismo frente a este belicismo, al resultar difícilmente conciliable con la Buena Nueva del Evangelio. Es el cansancio que conlieva la lucha española en los frentes más diversos. El cristianismo interior, abocado a veces a una determinada heterodoxia, es el primero en reflejarlo. Los ejemplos son sintomáticos. Alfonso de Valdés señala una transposición en el culto popular a los santos de los viejos cultos paganos, vencidos, pero nunca desaparecidos, y superpuestos al cristianismo. Ve en la devoción al Patrono de España un substitutivo del dios

Jeronimo de Mendieta. Carta a Fray Francisco Bustamante. Comisario General. Toluca, 1526. En Joaquin Garcia ICazbalceta. Colección de Documentos para la Historia de México. Vol. 2. Pág. 524. México, 1980.

in Jorge Manrique. A la muerte del Maestre de Santiago, Don Rodrigo Manrique.

19. Toribio Motolinia. Historia de los indios de la Nueva España. Trat. 1. Cap. 3. Pág. 21. 
Marte ${ }^{20} . Y$, antela escenografía habitual en los templos contemporáneos, orlados de banderas, escudos, lanzas y yelmos, pregunté si eran templos dedicados a Marte... ¿Qué tiene que hacer, decía yo, Jesucristo con estas insignias militares? "'. El gallo de Cristóbal de Villalón, sin matizaciones, mandará la milicia al infierno: sabe que los soldados que mueren en la guerra van principalmente al infierno porque en universal los toma la muerte en pecados que los llevan allá: en juegos, blasfemias, hurtos, ninguna guarda de los preceptos de la Iglesia, ni religión, enemistades, iras, enojos, pasiones luxurias, robos, sacrilegios y adulterios ${ }^{22}$. Los Doce, llegados después de la conquista cortesiana, se muestran conocedores de la gran falla que se abre ante su apostolado: la imposición por la fuerza de las armas de un cristianismo inicial. Aceptan los hechos consumados, debido a su visión providencialista, pero se esfuerzan en atenuar sus efectos impidiendo también su repetición. Fray. Martín de Valencia pretendió la propagación del evangelio por la Mar del Sur hacia el Asia, y obtuvo de Cortés la promesa de fletarle unas naves, para que alli predicasen el Evangelio...sin que precediese conquista de armas ${ }^{23}$. En 1560 eran habituales las entradas de franciscanos en la Nueva Galicia, sin acompañamiento militar ${ }^{24}$. En el túmulo que preside en México las exequias del Emperador, una doncella, personificación de la Iglesia Militante, conduce a Carlos $V$ ante la presencia de la Iglesia Triunfante, a quien dice: Propugnatorem meum tibi trado. Respondiendo la Iglesia Triunfante: Inter ubera mea commorábitur ${ }^{25}$.

Al final del xvi se cuestionará el propio patronazgo de Santiago, comenzando a dibujarse la femenina figura de Santa Teresa con su recogimiento en el castillo interior; claro que, a fin de cuentas, castillo ${ }^{26}$.

Y cuando Santiago Apóstol deje de cabalgar por la geografía peninsular, y los nuevos retablos de sus iglesias sean remisos en reservarle su calle central, el arte de la Nueva España seguirá presentándolo, centauro indómito, en su caballo blanco; la última cabalgada del Apóstol más allá del mar.

Los conquistadores de América más representativos procedían como Los Doce de Extremadura. Las encomiendas de las Ordenes de Santiago

\footnotetext{
Alfonso de Valdés. Diálogo de las cosas ocurridas en Roma. Pág. 139. Madrid, 1969.

AlFonso de Valdés. Diálogo de Mercurio y Carón. Pág. 17.

Caistóbal VILlalón. El Crótalon. Págs. 344, 345. Madrid, 1982.

Toribio Motolinia. Historia de los indios de la Nueva España. Trat. III. Cap. 5. Pág. 137.

A. Zurita. Memorial de 1560. En Joaquin Garcia ICazbalceta. Colección de Documentos.

Francisco Cenvantes Salazar. Túmulo Imperial de la Ciudad de México. 1560. Pág. 198.

J. Caro Baroja. Las formas complejas de la vida religosa. Tercera Parte. Cap. 17. Pág.
}

Vol. 2. Pág. 333. México, 1982. 427. Madrid, 1985. 
y Alcántara, poseian parte sustancial de la tenencia de la tierra. La actuación del conquistador estará próxima a la actuación de estas Ordenes y, ante los indigenas del Nuevo Mundo, proceden como los grandes maestres. Cortés el primero. Una concesión son sus Armas de Marqués, que presidieron la capilla mayor de la primera iglesia levantada en la Nueva España: San Francisco de México ${ }^{27}$.

Los episodios más recientes de la Reconquista española, guían a Hernán Cortés. Así, la semejanza entre la toma de Granada y la conquista de Tenochtitlán: Isabel erige sobre la colina de la Alhambra el templo de San Francisco; Cortés hace lo mismo sobre el Templo Mayor, utilizando sus sillares de tezontle. En ambos casos, los templos franciscanos son fundados sobre las creencias derrotadas. Hay como un deseo de franciscana paz después de la violencia, y un sometimiento del orgullo del conquistador a la humildad de Los Menores. Los creadores de la Unidad Nacional, y el Conquistador del imperio de Moctezuma profesan un franciscanismo sincero. ¡Cómo no va a invocar Cortés a Santiago, en los momentos claves de su campaña militar y considerarlo entre sus abogados protectores! ${ }^{28}$.

\section{PRESENCIA DEL APÓSTOL EN EL SANTO EVANGELIO DE LA NUEVA ESPAÑA}

La Provincia del Santo Evangelio adjudica a su patronazgo cuatro de sus conventos: Tlatelolco, Chalco, Xiutepec y Tecali ${ }^{29}$. Testimonia así la impronta santiaguista, aunque los gustos y alteraciones sociales o telúricas la hayan reducido iconográficamente.

Santiago de Tlatelolco es, con mucho, el conjunto que encierra un contenido más rico. Construido sobre la pirámide del dios de la guerra, es el

\footnotetext{
Cervantes recoge esta atmóstera espiritual al describir los tres santos caballeros de un retablo: San Martin, Santiago y San Pablo; el último será ya el más querido; pero, todavia hay una generosa concesión al pasado nacional, en boca del Caballero Andante: Este gran caballero de la cruz bermeja háselo dado Dios a España por patrón y amparo suvo, especialmente en los rigurosos trances que con los moros los españoles han tenido, asi le invocan y llaman como defensor suyo en todas las batallas que acometen, y muchas veces se le ha visto visiblemente en ellas derribando, atropellando destruyendo y matando los agarenos escuadrones; $y$ desta verdad te pudiera traer muchos ejemplos, que en las verdaderas historias españolas se cuentan. MIGUEL DE Cervantes. Don Quijote de la Mancha. Segunda Parte. Cap. 58. Barcelona, 1975.

") Jerónimo de Mendeta. Historia Eclesiástica Indiana. Vol. 2. Lib. 3. Cap. 18. Pág. 65.

2H Bernal Diaz del Castillo. Historia verdadera de la Conquista de la Nueva España. Cap. 204. Pág. 579. Madrid, 1976.

3.: Jerónimno de Mendieta. Relación. Págs. 127, 134. 192, 215.
} 
escenario de la última batalla durante la toma de Tenochtitlán. Después de la victoria se convertirá en el barrio indígena de la nueva Ciudad de México, opuesto al propio Tenochtitlán, o ciudad española. El Apóstol de la Cruz Bermeja, invocado desde el comienzo de las campañas, está presente en el epílogo de la misma.

Antes de la llegada de los españoles, la profecía azteca había presentido el cataclismo de la conquista, al incendiarse el templo que coronaba la pirámide ${ }^{30}$. Los conquistadores, como reafirmación del triunfo cristiano sobre la idolatría, determinan que en aquel gran cú habiamos de hacer la iglesia de nuestro patrón y guiador Señor Santiago e cupo mucha parte de la del solar del alto cú para solar de la santa iglesia ${ }^{31}$. Desde esa alta pirámide, y antes de la toma definitiva, Cortés presiente también su triunfo decisivo: Verdaderamente me da el corazón que desde aquí se han de conquistar grandes reinos y señorios, porque aqui está la cabeza donde el demonio principal tiene su silla; y rendida y sujeta esta ciudad, será fácil conquistar todo lo de adelante ${ }^{32}$.

Santiago, Antimahoma en la Reconquista de la Península, se transforma en Antihuitzilopochtli en el reducto de la resistencia azteca. Para levantar su iglesia se utilizaron los materiales de la pirámide, costeándose las obras con las joyas halladas en su cimentación. Tampoco hubo escrúpulos en la reutilización del arte islámico durante la Reconquista española. Arruinado el primer convento, a finales del XVI construye Torquemada la actual iglesia, con mano de obra indígena, incluyendo el retablo mayor, tan suntuoso que otro, no tal como él ${ }^{3.3}$. Desaparecido el retablo, pero conservado su relieve central con Santiago Matamoros, aquí conquistador de Tenochtitlán, su imagen ayuda a traducir su iconología novohispana.El Patrón de España, como San Pablo o San Bartolomé, apóstoles y mártires, tiene por símbolo una espada; pero, sólo el sentimiento religioso español hizo de su instrumento de martirio un arma ofensiva y defensiva de la misma fe.

El convento de Chalco, cerca de Texcoco, recuerda en su advocación de Santiago la alianza de sus habitantes con Cortés en el asalto definitivo a Tenochtitlán. Desaparecido su titular, un moderno grupo ecuestre de cartón piedra, es hoy el mejor testimonio de una fe sencilla en Santiago el Mayor (Lám. 1).

Diego Muñoz Camargo. Historia de Tlaxcala. Lib. 2. Cap. 1. Págs. 180, 181. Madrid, 1986 Bernal Diaz del Castillo. Historia verdadera. Cap. 92. Pág. 195.

Francisco Cervantes Salazar. Crónica de la Nueva España. Lib. 4. Cap. 20. Págs. 315, 316 Juan de Torquemada. Monarquia Indiana. Vol. 3. Lib. 17. Cap. 4. Pág. 215. México, 1975. 


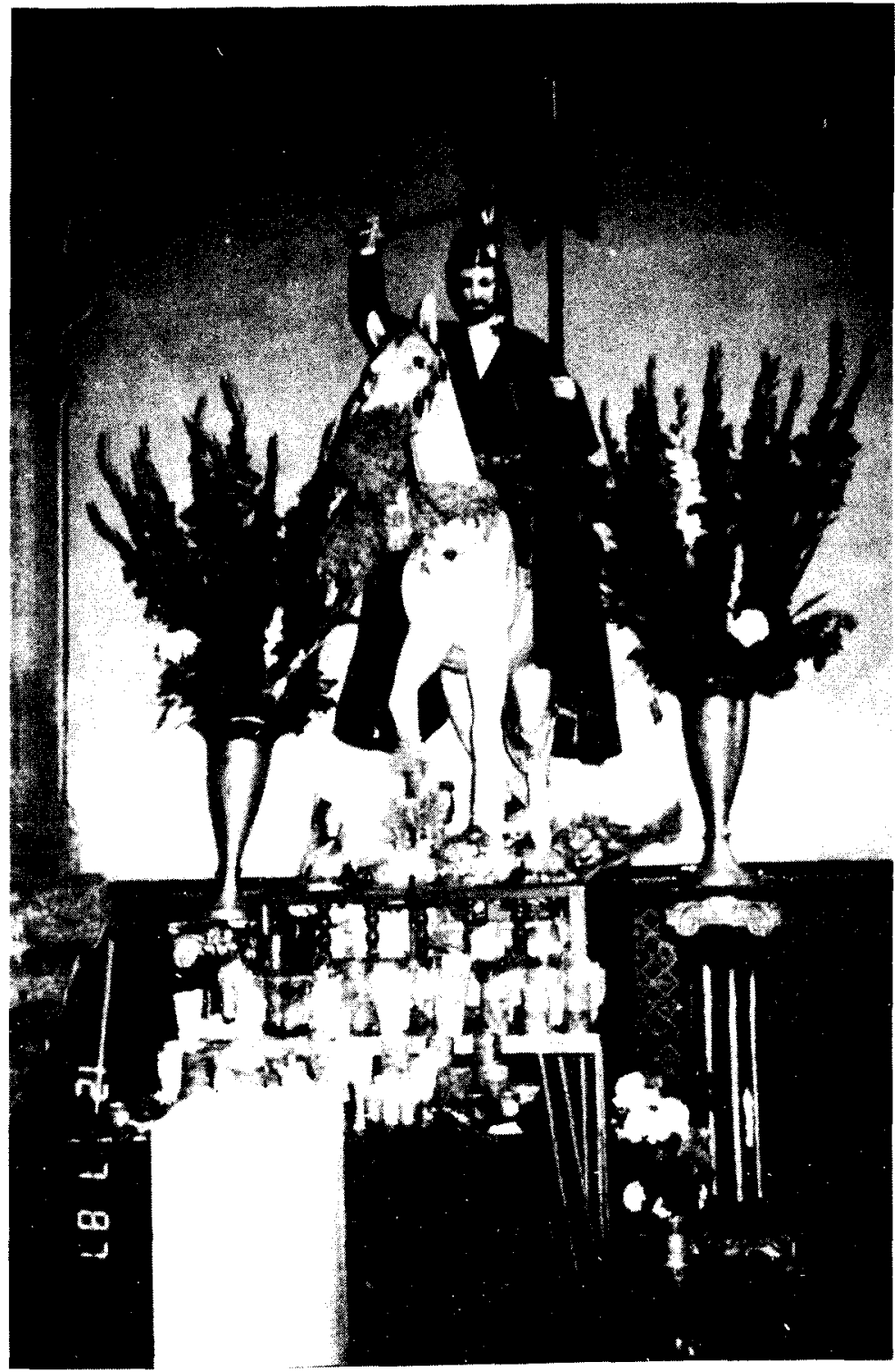

Fig. 1. Moderna estatua ecuestre de Santiago Caballero. Chalco. Edo. de México. Representa su primera iconografia en la Nueva España: sobre blanco caballo y peleando por los españoles. 
Xiutepec se cobijó bajo su patronazgo desde los primeros momentos, ya que sus habitantes reconocen obediencia al Rey de España ante el mismo Cortés, antes de la toma de la Capital.

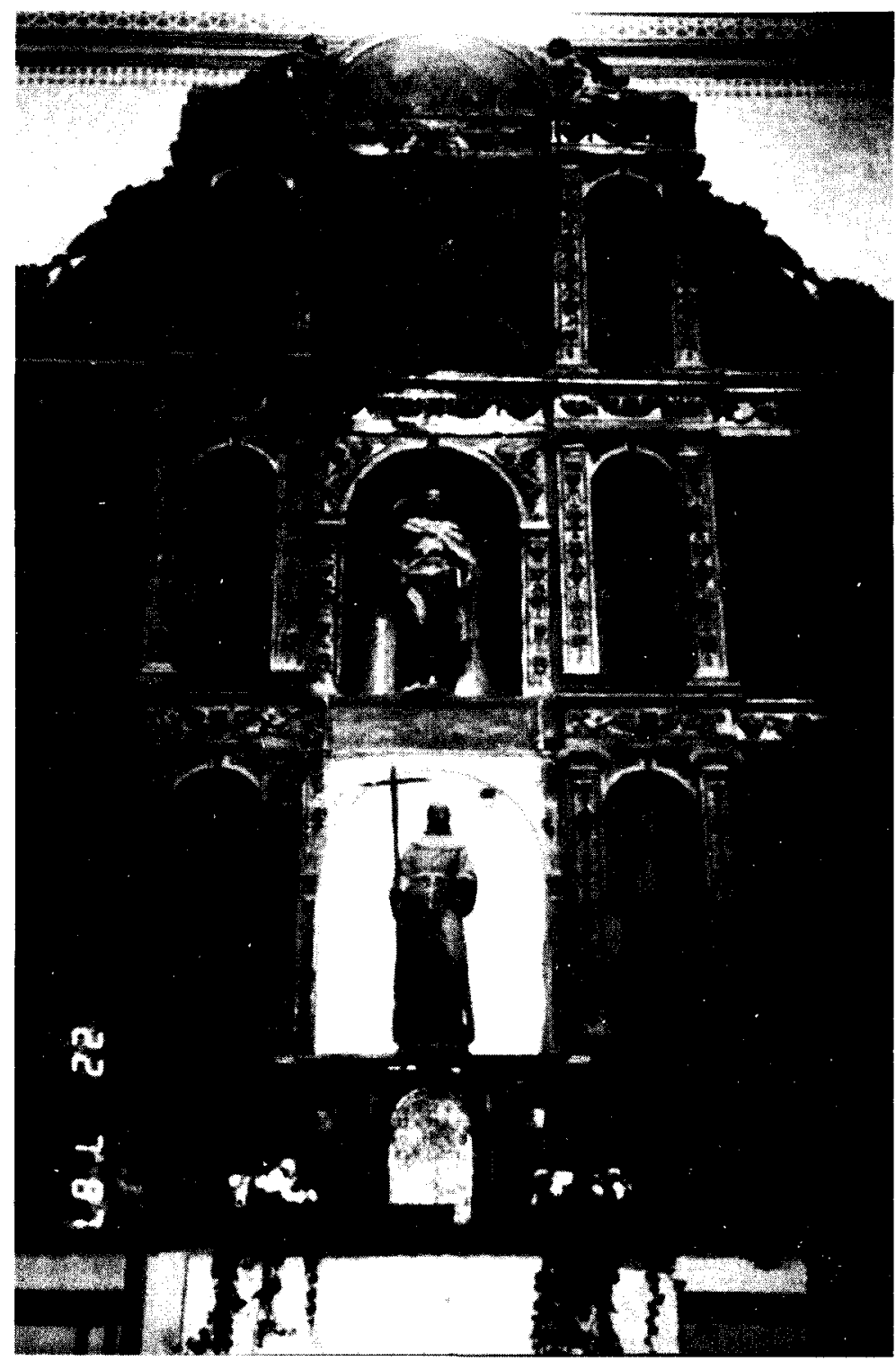

Fig. 2. Retablo de la parroquia de Tecali. Edo. de Puebla. Procede del extinto convento franciscano de Santiago. Lo preside la imagen del Apóstol Peregrino: bordón, escarcela y libro de su magisterio. 
Procedente de la iglesia conventual de Tecali (1580), la parroquia del lugar conserva un retablo con Santiago en iconografía de peregrino: zurrón, libro, bordón, esclavina y venera. (Lám. 2). Santiago se apea del caballo, desplazándose a pie, como la mayoría de sus devotos en el S. XVI. La Nueva España está ya pacificada y el Apóstol recobra la bondad con la que recibe en Compostela al peregrino. En la predella de todos los retablos del Xvı aparece con la misma indumentaria (Lám. 3). Una capilla posa de

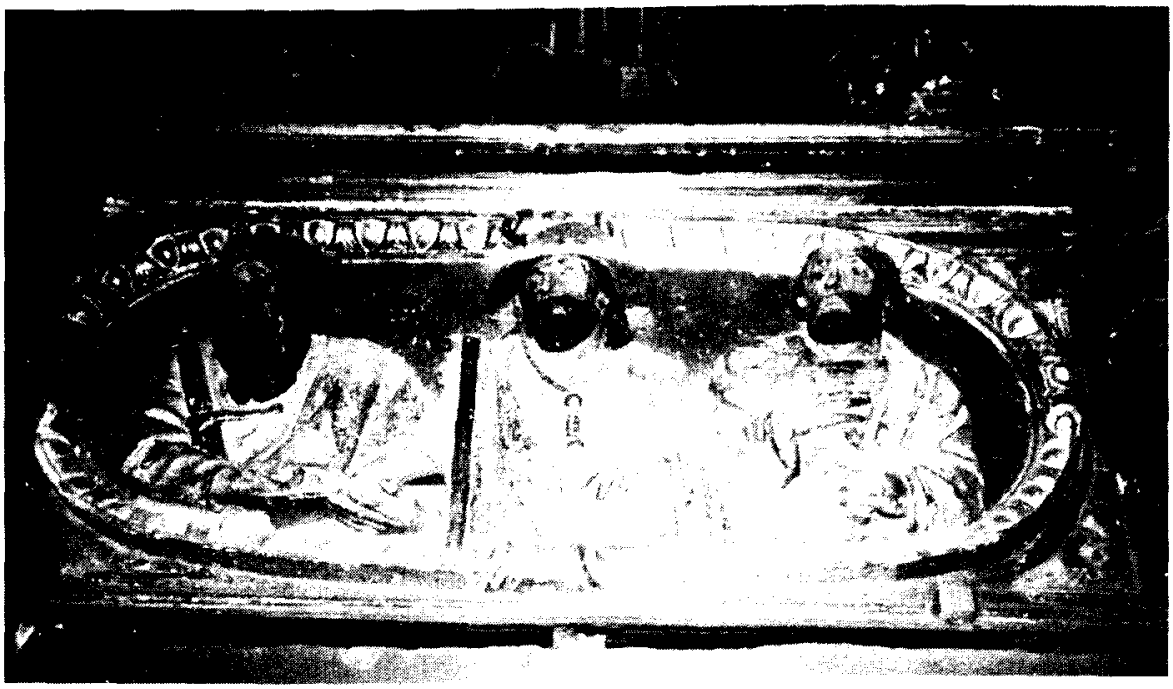

Fig. 3 Banco del retablo mayor de San Miguel de Huejozingo. Edo. de Puebla. En el centro, Santiago con bordón y sombrero de Peregrino.

Calpan, la de San Miguel, tiene como motivo ornamental la venera y la cruz de Santiago; y en el atrio de Huejozingo le dedican otra capilla (Lám.4). Muy poco, para la amplia documentación histórica que existe sobre su figura.

Identificado con la colonización española, su suerte ha sido la de sus simbolos. Pero, lo realmente emblemático es el proceso de transculturación que se percibe en el alma indígena ya cristianizada. Los caciques de San Esteban de Axapusco y Santiago de Tepeyahualco, solicitan en 1526 imágenes de San Esteban y Santiago. Sus efigies ilustran la alianza politica, en un gesto traducible como aceptación del nuevo orden: $Y$ os hacemos saber con el gusto que vamos a colocar a Señor San Sebastián y Santiago por patronos de nuestros pueblos ${ }^{34}$. El capitán de Cortés,

Real ejecutoria. Caciques de axapusco. 1526. En Joaguin Garcia Icazbalceta. Colección de Documentos. Vol. 2. pág. 17. 


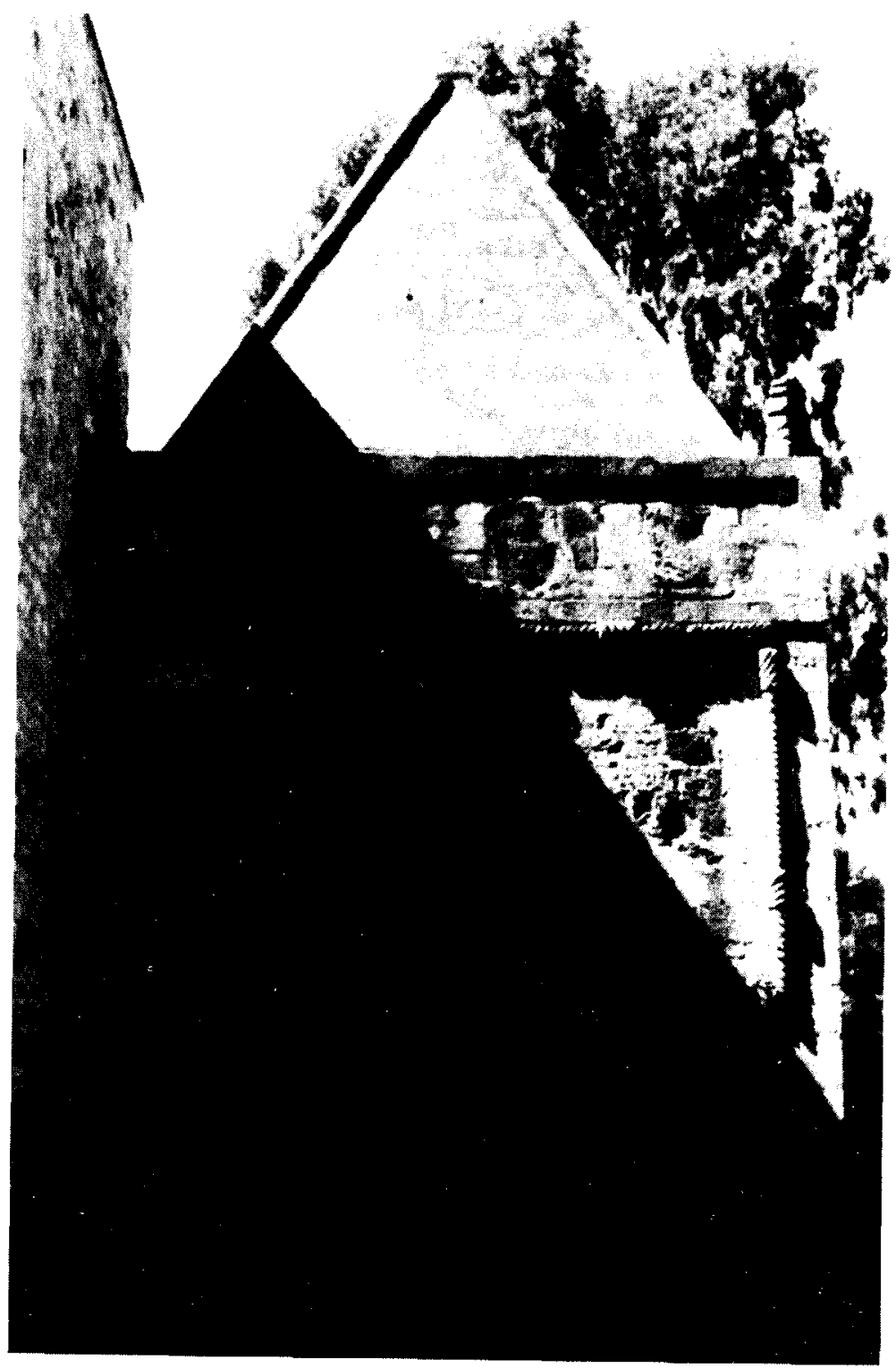

Fig. 4. Capilla posa de Santiago en el atrio de San Miguel de Huejozingo. Edo. de Puebla. Es la única capilla a la que, intencionalmente, le ha sido eliminada su iconografía. 
Andrés de Tapia, da por cierta la aparición de un hombre en un caballo rucio picado, e los indios comenzaron a huir e a nos dejar algún tanto ${ }^{35}$.

Al producirse el derrumbamiento de la fe azteca en sus dioses, que Octavio Paz ha visto como el gran cataclismo indígena: la huida de los dioses y la muerte de los jefes ${ }^{36}$, el catolicismo les hace participar en una nueva cosmovisión ejemplificada en Santiago, hasta el punto de que los tlaxcaltecas, aliados de Cortés, frente a los de Cholula que invocan a Quetzalcoatl, llamarán en su socorro a Santiago ${ }^{37}$, y de alli les quedó que hoy en dia hallándose en algún trabajo, los de Tlaxcala llaman al Señor Santiago. Estos tlaxcaltecas le verán aparecer en la batalla de Otumba ${ }^{38}$, de la misma manera que narra la historiografía peninsular su presencia en la supuesta batalla de Clavijo: y como lo reconocia la liturgia:

Tu bella cum nos cingerent,

Es visus ipso in proelio, equoque et ense acerrimus mauros furentes sternere ${ }^{39}$.

Las generosidades taumatúrgicas de Santiago según la tradición indígena de la Conquista, no se manifiestan en Motolinia, Sahagún o Mendieta, aunque la asuman como tradición piadosa; así lo demuestran los festejos de Tlaxcala del año 1538 donde Santiago comanda las tropas españolas que toman Jerusalén ${ }^{40}$. Torquemada y Vetancurt, últimos cronistas del periodo que analizamos, de sentido histórico menos riguroso, y exaltadores de las glorias nacionales, vuelven a interpretar las apariciones del Apóstol como ejemplo de la bondad de la Conquista ${ }^{41}$; aunque será durante el Barroco cuando se desarrolle plenamente.

Relación de Andres de Tapia. Pág. 559. En Joaquin Garcia ICazbalceta. Colección de Documentos. Vol. 2. Pág. 554.

Octavio Paz. El laberinto de la soledad. Cap. 5. Pág. 92. Madrid, 1982.

Diego Munoz Camargo. Historia de Tlaxcala. Lib. 2. Cap. 5. Pág. 214.

in Ibídem. Lib. 2. Cap. 6. Pág. 225.

"Wrev. Rom. Seraph. Jacobus Apostolus. Hymnus.

Toribio Motolinia. Historia. Trat. i. Cap. 15. Pág. 71.

Juan de Torquemada. Monarquía Indiana. Vol. I. Lib. 4. Cap. 69. Pág. 469. La intervención de Santiago en los episodios de la Conquista no es privativa de la literatura franciscana. El P. Acosta, en su Historia Natural y Moral de las Indias. Lib. 7. Cap. 27. Pág. 373, no muestra ningún reparo ante la intervención taumatúrgica del patrón de España: Por relaciones de muchos y por historias que hay, se sabe de cierto que en diversas batallas que los españoles tuvieron, asi en la Nueva España como en el Perú, vieron los indios contrarios, en el aire, un caballero con la espa. da en la mano, en un caballo blanco, pelando por los españoles; de donde ha sido y es tan grande la veneración que en todas las Indias tienen al glorioso apóstol Santiago. 
En definitiva, esta sensibilidad popular y medieval, se presenta para el azteca cristianizado más accesible que los esquemas del Renacimiento, y el franciscano lo sabía. Los misterios cristianos, visualizados gracias a la catequesis intuitiva que apelaba de continuo a los sentidos, hicieron posible que se grabaran profundamente en el alma indígena de la Nueva España. 